\title{
PERBAIKAN USAHA PETERNAKAN MELALUI INTRODUKSI INOVASI DAN PENINGKATAN MOTIVASI DI KELOMPOK TARUKO SAIYO, KECAMATAN PAUH PADANG
}

\section{LIVESTOCK BUSINESS IMPROVEMENT THROUGH INTRODUCTION INNOVATION AND IMPROVEMENT OF MOTIVATION IN THE TARUKO SAIYO GROUP, KECAMATAN PAUH PADANG}

\author{
Ediset $^{1 \text { )* }}$, Jaswandi ${ }^{2)}$, Rusmana ${ }^{3)}$, Amrizal Anas ${ }^{4)}$, Edwin Heriyanto ${ }^{5)}$ \\ ${ }^{1)}$ Fakultas Peternakan, Universitas Andalas. email: edisetjami80@ gmail.com \\ ${ }^{2)}$ Fakultas Peternakan, Universitas Andalas. email: Jaswandi_J@yahoo.co.id \\ ${ }^{3)}$ Fakultas Peternakan, Universitas Andalas. email: r.ningrat@faterna.unand.ac.id \\ ${ }^{4)}$ Fakultas Peternakan, Universitas Andalas, email: Amrizal.anas.123@yahoo.com \\ ${ }^{5)}$ Fakultas Peternakan, Universitas Andalas. email: edwin.heriyanto@yahoo.co.id
}

\begin{abstract}
ABSTRAK
Kegiatan pengabdian pada masyarakat ini dilakukan pada usaha peternakan sapi potong di kelompok Taruko Saiyo, Kelurahan Cupak Tangah, Kecamatan Pauh Kota Padang. Permasalahan dikelompok sasaran adalah adopsi inovasi oleh peternakan rendah karena kurang mendapat penyuluhan dan motivasi usaha anggota kelompok menurun. Tujuan dari kegiatan ini adalah 1) Introduksi inovasi peternakan dan 2) Meningkatkan motivasi angota kelompok Taruko Saiyo dalam menjalankan usaha peternakan sapi Potong. Transfer pengetahuan pada kelompok sasaran di lakukan dengan menggunakan metode penyuluhan melalui pendekatan ceramah dan sosialisasi. Hasil dari kegiatan adalah terjadi perubahan perilaku sasaran terutama pada aspek koqnitif, yaitu perubahan pengetahuan anggota kelompok Taruko Saiyo dari tidak mengetahui jenis jenis inovasi peternakan menjadi tahu, baik itu inovasi pada aspek pakan, aspek reproduksi maupun inovasi dalam bentuk program dan kebijakan pemerintah. Terjadi peningkatan motivasi anggota kelompok sasaran yang tergambar dari bergabungnya kembali anggota kelompok yang sebelumnya sudah tidak aktif dari keanggotaan dan terpilihnya kepengurusan baru di kelompok Taruko Saiyo.
\end{abstract}

Kata Kunci: Introduksi Inovasi, Inovasi Peternakan, Motivasi Usaha, Perbaikan Usaha, Usaha Peternakan

\section{ABSTRACT}

This community service activity is carried out in the beef cattle business in the Taruko Saiyo group, Cupak Tangah Village, Pauh District, Padang City. The problem in the target group is the low adoption of innovation by farms due to lack of counseling and decreased business motivation of group members. The objectives of this activity are 1) Introducing livestock innovations and 2) Increasing the motivation of the Taruko Saiyo group members in running a beef cattle business. Transfer of knowledge to target groups is carried out using extension methods through lecture and socialization approaches. The result of the activity is that there is a change in target behavior, especially in the competitive aspect, namely a change in the knowledge of the Taruko Saiyo group members from not knowing the types of livestock innovations to knowing, both innovations in the aspects of feed, aspects of reproduction and innovation in the form of government programs and policies. There was an increase in the motivation of target group members as reflected in the rejoining of group members who had previously been inactive from membership and the election of new management in the Taruko Saiyo group.

Keywords: Introduction of Innovations, Livestock Innovation, Business Motivation, Business Improvement, Livestock Business 


\section{PENDAHULUAN}

Kelompok tani Taruko Saiyo yang berada di Kelurahan Cupak Tangah, Kecamatan Pauh Kota Padang memiliki beberapa divisi usaha, seperti usaha peternakan sapi, usaha peternakan itik dan usaha perikanan. Usaha ternak itik dan perikan hanya dilakukan oleh beberapa anggota saja, sedangkan untuk usaha peternakan sapi dijalankan oleh hampir semua anggota, dengan skala kepemilikan 25 ekor dan bahkan ada anggota yang memiliki populasi yang mencapai 30 ekor. Jumlah anggota kelompok yang tercatat di pengurus berjumlah sebanyak 15 orang dengan latar belakang pekerjaan utama yang berbeda.

Awalnya usaha peternakan sapi potong yang dijalankan oleh kelompok Taruko Saiyo dilakukan secara berkoloni, namun akhir akhir ini anggota sudah menjalankan usahanya secara individual dan bahkan ada beberapa anggota yang keluar dari kelompok. Penyebab keluarnya anggota dari kelompok diantaranya disebabkan oleh tidak adanya perubahan dan kemajuan yang dirasakan oleh anggota selama bergabung dalam kelompok, terutama dari peningkatan produktifitas usaha. Produktifitas usaha peternakan disamping ditentukan oleh pengetahuan dan keterampilan tentang teknis beternak juga ditentukan oleh motivasi peternak dan inovasi peternakan yang diadopsi. [1] Produktivitas berbagai sektor utama di Indonesia relatif tidak tinggi, salah satu faktor penyebabnya adalah kontribusi inovasi yang minim dalam proses produksi.

Motivasi usaha yang berorientasi ekonomis akan menjadikan usaha peternakan sebagai usaha utama dalam rumah tangga peternak, yang pada akhirnya akan peningkatan pendapatan. Demikian juga bila usaha peternakan sapi dijalankan berbasis inovasi tentu akan dapat mengembangkan usaha, karena melalui adopsi inovasi tersebut pembaharuan pada semua aspek teknis pemeliharaan ternak sapi dapat terjadi. [2] Inovasi diartikan sebagai ide-ide baru, praktek-praktek baru atau objek-objek yang dapat dirasakan sebagai sesuatu yang baru oleh individu atau masyarakat sasaran penyuluhan.

Perbaikan usaha peternakan sapi pada kelompok sasaran dilakukan dengan metode penyuluhan melalui pendekatan ceramah dan sosialisasi tentu akan dapat meningkatkan produktifitas usaha, karena selama ini kelompok sasaran belum pernah mendapatkan penyuluhan dari stake holder terkait, baik itu yang berasal dari dinas pertanian, pihak swasta maupun dari kelompok akademisi. Untuk itu pelaksanaan pengabdian pada kelompok sasaran perlu dilakukan agar terjadi perubahan perilaku pada peternak, khususnya perubahan pada aspek pengetahuan dan sikap, baik itu untuk mengadopsi inovasi maupun motivasi dalam menjalankan usahanya.

Berdasarkan uraian diatas maka dirumuskan beberapa permasalahan yang dihadapi oleh peternak sasaran sebagai berikut : 
1. Bagaimana meningkatkan pengetahuan peternak tentang inovasi peternakan yang ada pada aspek teknis pemeliharaan sapi potong di kelompok peternak sapi Taruko Saiyo, Kecamatan Pauh Kota Padang.

2. Bagaimana menimbulkan kembali motivasi peternak dalam menjalankan usaha ternak sapi potong dikelompok Taruko Saiyo, Keamatan Pauh Kota Padang.

Tujuan kegiatan pengabdian pada masyarakat ini adalah :

1. Meningkat pengetahuan peternak di kelompok Taruko Saiyo tentang inovasi pada aspek teknis peternakan dan mendorong peternak agar mau dan mampu mengadopsi inovasi yang telah di introduksikan.

2. Menimbulkan kembali motivasi anggota kelompok Taruko Saiyo, baik untuk menjalankan usaha secara berkelompok maupun motivasi untuk mengadopsi inovasi peternakan.

\section{METODE PELAKSANAAN KEGIATAN}

Metode yang dipergunakan dalam kegiatan pengabdian untuk membantu menyelesaikan permasalahan yang dihadapi oleh anggota kelompok yaitu:

\section{a. Temu Lapangan}

Temu lapang merupakan pertemuan antara petani/peternak dengan peneliti untuk tukar menukar informasi berupa teknologi baru atau pemecahan masalah yang terjadi ditingkat usahatani [3]. Pertemuan di lakukan areal perkandangan salah seorang anggota kelompok yang representatif untuk melakukan diskusi dan sekaligus apabila dibutuhkan media percontohan sudah tersedia.

Temu lapangan ini bertujuan untuk berdiskusi dan tukar pikiran antara narasumber yang berasal dari tim pengabdian dengan kelompok sasaran kegiatan, dengan metode ini posisi narasumber sejajar dengan sasaran serta akan menimbulkan komunikasi dua arah yang berdampak baik terhadap pemahaman materi bagi sasaran. Materi yang disampaikan dengan metode ini adalah introduksi inovasi peternakan

\section{b. Ceramah/sosialisasi dan bimbingan}

Metode ini diterapkan untuk penyelesaian permasalahan kelompok yang terkait dengan motivasi usaha yang cendrung menurun.[4] Beberapa kelebihan dari ceramah, yaitu penceramah dapat mengubah isi pidato, sesuai dengan keperluan dan minat hadirin, penceramah dapat memperhatikan tanggapan hadirin, hadirin memdapatkan penjelasan serta hadirin diberi kesempatan untuk bertanya.

Metode ini di awali penyampaian materi oleh narasumber dengan model komunikasi satu arah, pasca penyampaian keseluruhan materi disediakan sesi diskusi dan tanya jawab bagi peserta kegiatan. Peserta diberikan kesempatan secara luas untuk bertanya dan boleh bertanya secara berulang kali. Metode ini ditetapkan untuk untuk menyampaikan materi terkait dengan motivasi 


\section{HASIL DAN PEMBAHASAN}

\section{Introduksi Inovasi Peternakan}

Materi ini bertujuan

untuk

memoderenisasi usaha peternakan sapi yang ada di kelompok Taruko Saiyo, adapun inovasi yang diperkenalkan pada peternak adalah inovasi yang ada pada aspek pakan, inovasi reproduksi dan inovasi yang berkaitan dengan program, terutama program dalam bentuk bantuan dari pemerintah. [2] mengartikan inovasi sebagai: ide-ide baru, praktek-praktek baru, atau obyek-obyek yang dapat dirasakan sebagai sesuatu yang baru oleh individu atau masyarakat sasaran penyuluhan.

Tujuan kegiatan introduksi inovasi adalah agar anggota kelompok sasaran memiliki pengetahuan, kemudian memiliki kemauan untuk mengadopsi dan memiliki keterampilan untuk menerapkan inovasi yang telah di introduksikan. Kegiatan penyuluhan ini mengintroduksikan beberapa jenis inovasi peternakan, diantaranya adalah inovasi pakan seperti Urea Molases Blok (UMB), Fermentasi Jerami dan Fermentasi Bonggol pisang.

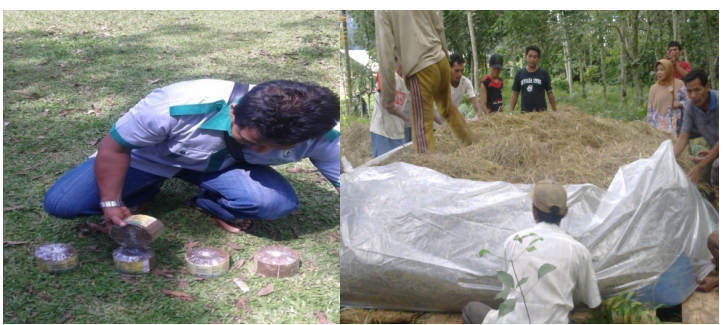

Gambar 1. Introduksi inovasi peternakan pada aspek Pakan (UMB dan amoniasi jerami)

Inovasi reproduksi yang di introduksikan adalah Inseminasi Buatan (IB) dan Transfer Embrio (TE), tujuan penyampaian dan memperkenalkan ini inovasi pada aspek reproduksi adalah untuk meningkatkan kualitas maupun kuantitas dari ternak sapi. Peningkatan kualitas dalam bentuk daging maupun anak yang dilahirkan, sedangkan peningkatan kuantitas adalah dalam bentuk pertambahan populasi.

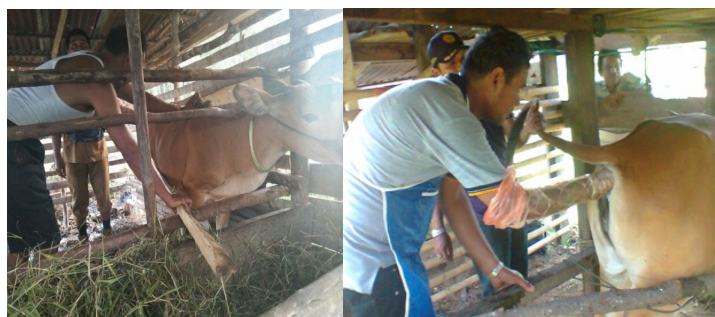

Gambar 2. Introduksi Inovasi Reproduksi IB dan TE

Inovasi dalam bentuk program dan kebijakan pemerintah juga di perkenalkan, yaitu program KUPS (Kredit Usaha Pembibitan Sapi), Kredit Usaha Rakyat (KUR), Program Kemitraan dan Pertanian terintegrasi (Integrated Farming). Perkenalan dari inovasi dalam bentuk program ini bertujuan untuk menambah pengetahuan peternak cara mengakses permodalan untuk menjalankan usaha peternakan serta mengembangkan usaha secara terintegrasi.

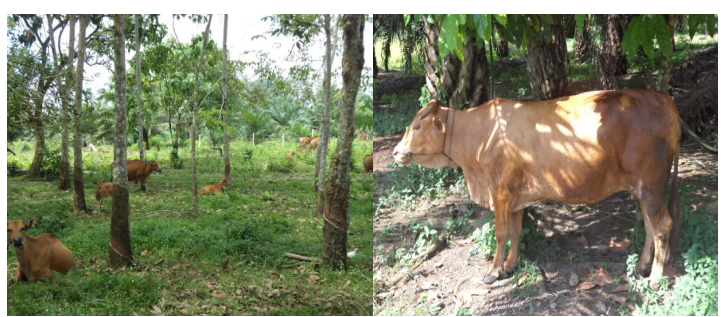

Gambar 3. Inovasi peternakan (Integrated Farming)

Kegiatan introduksi inovasi dihadiri oleh banyak anggota kelompok dan bahkan ada sebagian yang berasal dari masyarakat biasa yang berkeinginan untuk memelihara ternak sapi. Jumlah peserta yg hadir adalah 25 orang, ditambah dengan tim pengabdi 
sebanyak 3 orang dan mahasiswa sebanyak 3 orang pula. Peserta terlihat begitu responsip terhadap materi yang disampaikan, hal itu terjadi karena selama ini sebagian peserta belum mengetahui inovasi inovasi peternakan yang diperkenalkan tersebut.

Hasil kegiatan penyuluhan ini adalah bertambahnya wawasan dan pengetahuan peternak sasaran kegiatan penyuluhan terkait dengan jenis jenis inovasi yang bisa di adopsi dalam menjalankan usaha peternakan sapi potong, beberapa cara pembuatan inovasi sederhana, bahan, manfaat serta kelebihan dan kekurangan dari inovasi. Pada kesempatan itu peternak sasaran juga meminta agar untuk kegiatan pengabdian berikutnya dapat dilaksanakan pelatihan untuk pembuatan inovasi pakan. [5] untuk meningkatkan pengetahuan dan keterampilan dari sasaran dalam menginflementasikan teknologi, perlu dilakukan penyuluhan, pelatihan dan percontohan sehingga peternak mempunyai solusi dari setiap permasalahan yang dihadapi.

\section{Peningkatan Motivasi Usaha Anggota Kelompok}

Paparan narasumber terkait dengan motivasi usaha adalah manfaat usaha berkelompok. Manfaat peternak tergabung dalam satu kelompok [6] adalah menumbuh kembangkan kelompok tani melalui peningkatan akses permodalan bagi petani, peningkatan posisi tawar, pembinaan kepada organisasi kelompok, serta peningkatan efisiensi dan efektivitas usahatani, serta meingkatkan kapasitas SDM petani melalui berbagai kegiatan pendampingan, dan pelatihan yang dirancang secara khsusus bagi pengurus dan anggota kelompok tani.

Materi berikutyna yang diberikan adalah berkaitan dengan skala usaha, manfaat ekonomis, sosial dan budaya, serta perhitungan sederhana tentang penghasilan dari menjalankan usaha ternak sapi. Skala usaha tentu penting untuk disampaikan karena dengan usaha yang skala ekonomi atau skala bisnis akan menggiring pemilik untuk menjadikan usaha tersebut sebagai usaha pokok/utama rumah tangga. Nara sumber juga menjelaskan bahwa dengan memelihara ternak sapi tidak hanya memberikan manfaat secara ekonomis tetapi juga manfaat sosial seperti mengangkat harkat dan martabat pemilik di tengah tengah masyarakat, sedangkan manfaat dilihat dari aspek budaya tentu menjaga tradisi untuk tetap memelihara ternak sapi.

\section{Pendekatan dalam penyampaian} materi motivasi adalah pendekatan ceramah dan diskusi, tujuannya adalah agar narasumber memiliki keleluasaan dalam memberikan motivasi pada peserta yang hadir. [7] motivasi kewirausahaan melalui penyuluhan dapat merubah aspek koqnitif peternak sasaran tentang orientasi usaha yang dilakukan, sehingga hal ini akan berdampak pada skala usaha atau jumlah populasi ternak sapi yang dipelihara. 


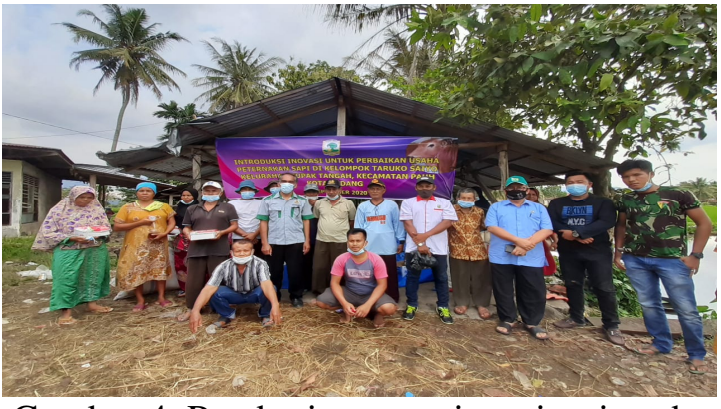

Gambar 4. Pemberian materi motivasi usaha

Penyampaian materi dan diskusi tentang motivasi ini juga dihadiri oleh peserta, 20 orang. Tim pengabdian yang terdiri dari dosen dan mahasiswa kewirausahaan, dimana dosen berjumlah 2 orang dan mahasiswa sebanyak 4 orang. Meskipun tidak mendiskusikan hal hal teknis yang berkaitan dengan pemeliharaan ternak sapi, namun penyampaian materi motivasi mendapat respon yang positif dari peserta, terlihat dari keseriusan dan antusias selama kegiatan berjalan.

Hasil dari kegiatan ini terlihat dari keinginan peternak untuk kembali menata usaha peternakannya yang sebelumnya sudah terhenti dan kemudian juga membangkitkan keinginan dari beberapa peserta yang bukan anggota dan belum memiliki usaha peternakan untuk mencoba menekuni usaha ini, terakhir pertemuan ini menimbulkan semangat baru bagi anggota kelompok yang sebelumnya sudah mulai vakum. Bukti munculnya motivasi dari anggota kelompok adalah dipilihnya pengurus baru secara aklamasi.

\section{KESIMPULAN}

1. Peternak anggota kelompok Taruko Saiyo,

Kecamatan Pauh Kota Padang mengalami peningkatan pengetahuan pada beberapa jenis inovasi peternakan, baik baik itu inovasi pada aspek pakan, aspek reproduksi maupun inovasi dalam bentuk program dan kebijakan pemerintah.

2. Terjadi peningkatan motivasi anggota kelompok sasaran yang tergambar dari bergabungnya kembali anggota kelompok yang sebelumnya sudah tidak aktif dari keanggotaan dan terpilihnya kepengurusan baru di kelompok Taruko Saiyo.

\section{SARAN}

Stake holder terkait, baik itu Dinas Pertanian, akademisi Peternakan maupun pihak perbankan sebagai penyalur bantuan dan kredit sebaiknya membina kelompok kelompok peternak secara berkelanjutan sesuai dengan tugas pokok dan fungsinya masing masing.

\section{UCAPAN TERIMAKASIH}

Tim Pengabdian mengucapkan terima kasih dan apresiasi pada kelompok Taruko Saiyo yang telah berpartisipasi aktif untuk kelancaran kegiatan, serta ucapan terima kasih kepada pimpinan Fakultas Peternakan Universitas Andalas yang telah mendukung pembiayaan kegiatan pengabdian melalui dana Dipa Fakultas tahun 2020.

\section{REFERENSI}

[1] Indraningsih, K.S. 2017. Strategi Diseminasi Inovasi Pertanian dalam Mendukung

Pembangunan Pertanian. Jurnal Litbang Pertanian. Forum Penelitian Agro Ekonomi, Vol. 35. No. 2. Hal : 107-123.

[2] Rogers dan Shoemaker. 1995. Communication of Innovation A Cross Cultural Approach. Coller Macmilan Publisher. London.

[3] Anwar, S. Fuad, M dan Amrizal, A. 
2009. Ilmu Penyuluhan Pertanian. Universitas Andalas. Padang.

[4] Hawkins, H.S. dan A.W. Van Den Ban. 1999. Penyuluhan Pertanian, Diterjemahkan oleh Agnes Dwina Herdiasti. Kanisius, Jakarta.

[5] Ediset dan E. Heriyanto. 2019. Introduksi Teknologi Peternakan di Nagari Koto Padang Kabupaten Dharmasraya. Jurnal Hilirisasi Ipteks. Vol. 2, No 3b, Hal : 325-332.

[6] Ramdhani, H., S. A. Nulhaqim dan M. Fedryansyah. 2015. Peningkatan Kesejahteraan Petani dengan
Penguatan Kelompok Tani. Jurnal Prosiding Penelitian dan Pengabdian kepada Masyarakat, Unpad. Vol. 02, No. 03, Hal : 423-429

[7] Ediset, Jaswandi, E. Heriyanto dan B. Basyar. 2017. Peningkatan Produktivitas Peternak Sapi di Daerah Transmigrasi Lubuk Aur Sitiung I Kabupaten Dharmasraya. Jurnal Logista Fateta. Vol 1, No. 1, Hal: 11-19 